\title{
ESCLEROQUERATITIS Y CARCINOMA ESCAMOSO CONJUNTIVAL INVASIVO
}

\section{SCLEROKERATITIS AND INVASIVE CONJUNCTIVAL SQUAMOUS CELL CARCINOMA}

\author{
ARTEAGA-SÁNCHEZ A ${ }^{1}$, TOLEDANO-FERNÁNDEZ N² ${ }^{2}$, DÍAZ-VALLE D ${ }^{3}$, \\ FERNÁNDEZ-ACEÑERO MJ ${ }^{4}$, HIJÓS-GASTÓN M ${ }^{5}$
}

\section{RESUMEN}

Objetivo/método: Se presenta una escleritis nodular anterior de dos años de evolución en una mujer de 74 años, que desarrolla posteriormente un carcinoma conjuntival escamoso invasivo, en la zona adyacente al nódulo de escleritis.

Resultados/conclusiones: El desarrollo de un carcinoma escamoso conjuntival que tiene como precedente la aparición adyacente de una escleritis nodular anterior que no respondió al tratamiento. En nuestra paciente la escleritis iniciada dos años antes pudo enmascarar el carcinoma escamoso, retrasando el diagnóstico y permitiendo la invasión orbitaria del tumor. Ante una escleritis de presentación atípica o sin respuesta al tratamiento debe considerarse la posibilidad de una neoplasia.

Palabras clave: Escleritis, carcinoma de células escamosas, invasión ocular-conjuntiva-uveitisescleroqueratitis.

\section{ABSTRACT}

Purpose/methods: To describe one case of invasive squamous cell carcinoma of the conjunctiva in a 74-year-old woman, who two years previously had presented with a lesion which appeared to be an anterior nodular scleritis.

Results/conclusions: An anterior nodular scleritis, which did not respond to therapy, preceded the development of a squamous cell carcinoma of the conjunctiva adjacent to it. In our patient, the conjunctival squamous cell carcinoma could have masqueraded as a scleritis, delaying the correct diagnosis and allowing orbital spread of the tumor. A diagnosis of neoplasia must be considered when a scleritis shows an atypical appearance or does not respond to the usual therapy (Arch Soc Esp Oftalmol 2007; 82: 237-240).

Key words: Scleritis, squamous cell carcinoma, ocular invasion, conjunctiva-uveitis-sclerokeratitis.

\footnotetext{
Recibido: 2/1/06. Aceptado: 26/3/07.

Hospital General de Móstoles. Madrid. España.

1 Licenciado en Medicina.

2 Licenciado en Medicina. Hospital de Fuenlabrada. Madrid.

3 Doctor en Medicina. Hospital Clínico Universitario San Carlos. Madrid.

4 Doctor en Medicina.

${ }^{5}$ Licenciado en Medicina. Hospital Universitario Puerta de Hierro. Madrid.

Correspondencia:

Ángel Arteaga Sánchez

C/. Alfredo Marqueríe, 47, esc. 4, 2. ${ }^{\circ} \mathrm{B}$

28034 Madrid

España

E-mail: artesanc@yahoo.com
} 


\section{INTRODUCCIÓN}

El carcinoma conjuntival de células escamosas, es un tumor poco frecuente (1) que se desarrolla en zonas de transición de la superficie ocular (conjuntiva o córnea), y se manifiesta como una masa gelatinosa, de color rojizo-grisácea (2). Ocasionalmente puede iniciarse sin masa evidente y pasar largo tiempo desapercibida o enmascararse como una escleritis. Se presenta una inusual forma de aparición de carcinoma escamoso conjuntival en el entorno de una escleritis anterior de larga evolución y refractaria al tratamiento. La demora en el diagnóstico del carcinoma, dado el solapamiento de los signos de alarma del carcinoma con los de la escleroqueratitis propició la extensión orbitaria.

\section{CASO CLÍNICO}

Mujer blanca de 71 años, sana, que es diagnosticada de escleritis nodular anterior en ojo izquierdo (OI). La agudeza visual (AV) en ese momento en ojo derecho (OD) es de 20/30 y en OI de 20/50.

El nódulo escleral blanquecino de $1,5 \mathrm{~mm}$ se localiza en sector nasal inferior a $2 \mathrm{~mm}$ de limbo, con exploración oftalmológica normal. Realizado el estudio sistémico, se aprecia una leve disminución de IgM y linfocitosis del 48\%, siendo normales el resto de pruebas específicas de uveítis. Se comienzaría un tratamiento empírico con esteroides orales, con respuesta paradójica, y claro empeoramiento clínico. La paciente rechaza el uso de inmunosupresores. A los 6 meses de tratamiento con esteroides sin haber controlado los síntomas definitivamente, se detectó una presión intraocular (PIO) en el OI de $30 \mathrm{mmHg}$ sin respuesta al tratamiento con hipotensores. Con 10 meses de evolución el proceso empeoró, con una mayor elevación nodular, edema corneal y ulceración de la conjuntiva perilesional (fig. 1). Se desestimó una biopsia ante la negativa de la paciente y el potencial riesgo de perforación. A los 16 meses de evolución se inició tratamiento con Metrotexate con un notable empeoramiento clínico, y PIO de $45 \mathrm{mmHg}$, refractaria al tratamiento. A los 21 meses de evolución, el nódulo escleral ha cambiado, apareciendo una desestructuración escleroconjuntival y una masa aplanada de aspecto gelatinoso de color rojizo (fig. 2). Se realizó biopsia conjuntival que confirmó la presencia de un carcinoma escamoso conjuntival. En el TC orbitario y de cuello se constató la afectación de recto medial y

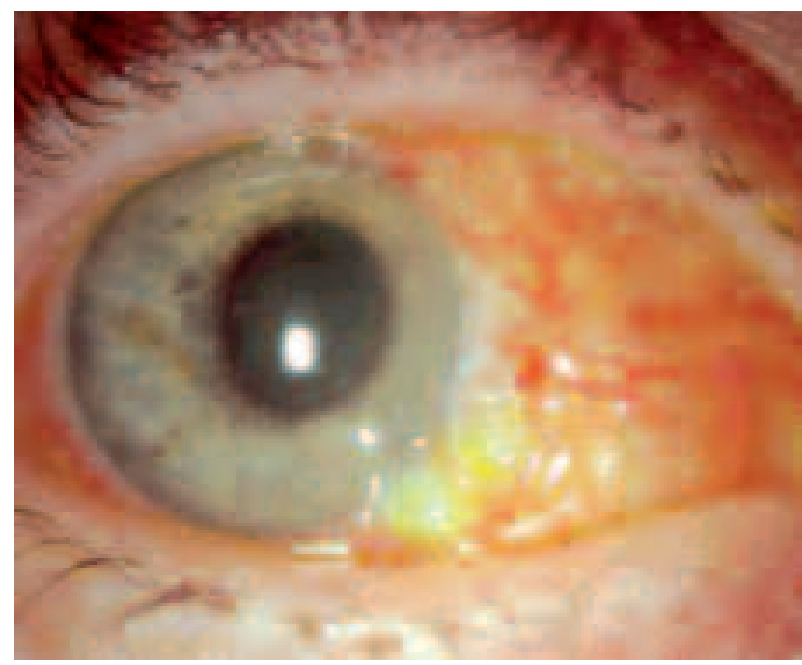

Fig. 1: Estadio avanzado de la lesión con nódulo de escleroqueratitis y lesión conjuntival reactiva y sospechosa.

el saco lagrimal del OI. Dada la evolución del proceso se efectúa una exenteración con colgajo rotacional de músculo temporal. En el estudio anatomopatológico se observó la lesión nodular escleral y el carcinoma conjuntival adyacente (figs. 3 y 4). Al año de la cirugía la paciente permanece asintomática sin recidiva y el estudio de extensión es negativo.

\section{DISCUSIÓN}

Las lesiones neoplásicas del epitelio escamoso de la conjuntiva incluyen displasias 2 , neoplasias intraepiteliales y carcinomas de células escamosas.

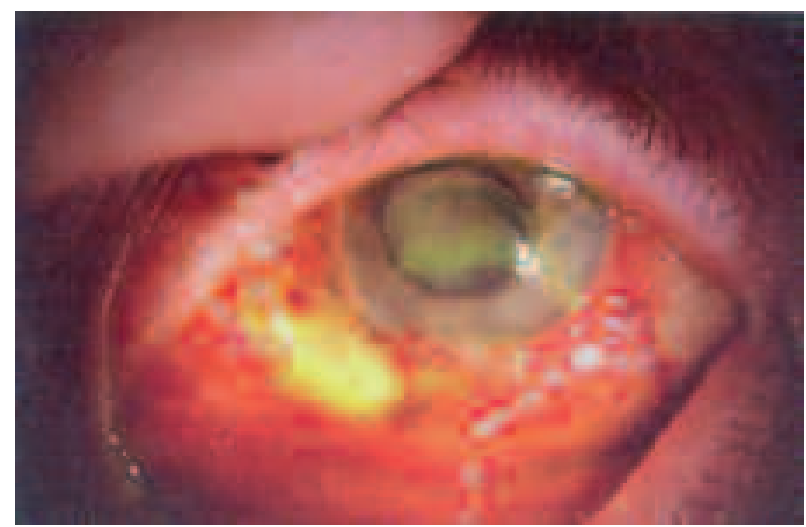

Fig. 2: Se aprecia empeoramiento de la lesión escleral con afectación corneal y crecimiento conjuntival. Previo a la realización de biopsia conjuntival. 


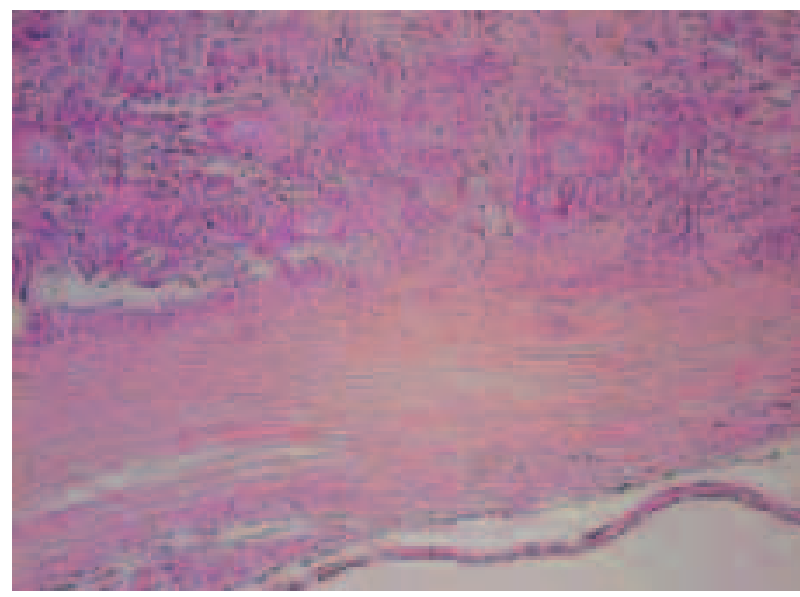

Fig. 3: En la muestra (microscopía óptica hematoxilina-eosina x100) se aprecian nidos de células tumorales queratinizadas (en círculo azul) compatible con carcinoma escamoso. Se observa poca inflamación en la zona tumoral al no detectarse células linfocitarias alrededor de los nidos tumorales.

El carcinoma de células escamosas tiene una incidencia baja, entre 0.02 y $3.5 / 100.00$ disminuyendo en latitudes altas (3). Aparece en la 6. ${ }^{\mathrm{a}}-7$. $^{\mathrm{a}}$ década de la vida, y se localiza en áreas expuestas interpalpebrales, en zonas de transición del epitelio (limbo). Los factores de riesgo asociados a su presentación son : la exposición a la luz UVA y el xeroderma pigmentoso (sobre todo en pacientes jóvenes). La existencia de quemaduras y heridas en

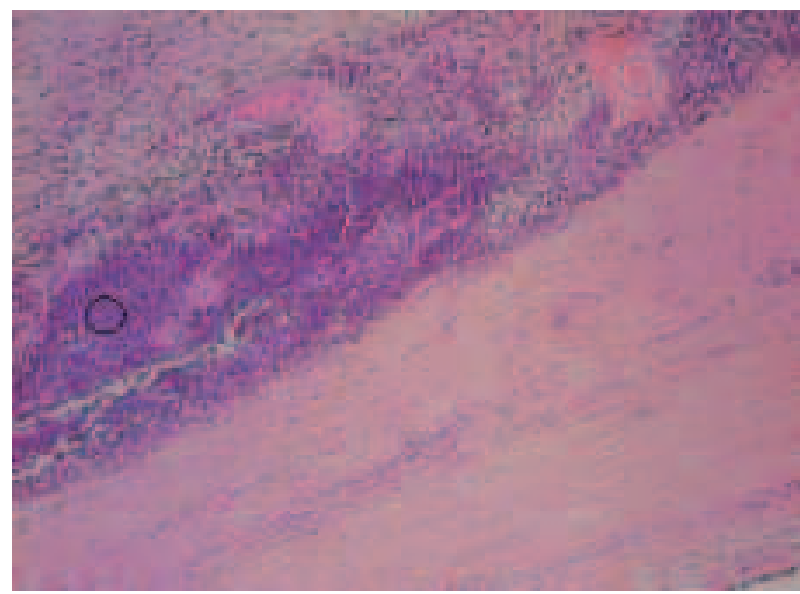

Fig. 4: En este corte (microscopía óptica hematoxilinaeosina x100) observamos las dos lesiones: la zona de escleroqueratitis (con círculo negro) con infiltrado inflamatorio y algún nido de células tumorales (en círculo azul) con menor infiltrado linfocitario. superficie ocular podrían asimismo facilitar la aparición del carcinoma. El carcinoma escamoso conjuntival invasivo viene definido por la infiltración de la membrana basal por células atípicas. La invasión orbitaria aparece en un 12-16\% (4).

Aunque la manifestación clínica del carcinoma como una masa rojiza, de aspecto gelatinoso, en región interpalpebral es muy sugerente; ocasionalmente se puede presentar de forma atípica como una lesión más blanquecina, difusa confundiéndose con otros procesos y generando un síndrome de enmascaramiento (2).

Se han descrito pocos casos de carcinoma conjuntival escamoso invasivo asociado a escleritis (5) o escleroqueratitis (2). La excepcionalidad del caso radica en la presentación de la escleroqueratitis nodular y la aparición tardía de un carcinoma conjuntival escamoso, adyacente, como se demostraría posteriormente en el análisis anatomopatológico. En dicho estudio se observa el proceso tumoral (fig. 3) con abundantes nidos de células con queratina y mitosis (rápido crecimiento) y poco infiltrado inflamatorio linfocitario. Aquí el proceso tumoral crece desde la superficie (conjuntiva) y no desde zonas esclerales o corneales. En la figura 4 se observa la confluencia de las dos lesiones, la escleral con su acúmulo de linfocitos sin células tumorales y lejos de ella un nicho tumoral que no guarda relación con la lesión previa.

El comportamiento atípico de una escleritis debe hacernos considerar otros diagnósticos como el carcinoma conjuntival. Sigue siendo motivo de discusión si la escleritis es la precursora del carcinoma, aduciendo una causa irritativa local producida por la inflamación crónica del área, si son dos procesos independientes que coinciden en el tiempo formando un proceso de enmascaramiento o por último si desde el inicio la lesión fuese un tumor con gran componente inflamatorio.

En cualquier caso el retraso en el diagnóstico de un carcinoma escamoso conjuntival de presentación atípica propicia su extensión infraorbitaria.

Señalar como conclusión, que se debe considerar el diagnóstico de neoplasia ante una escleritis con presentación atípica o sin respuesta al tratamiento.

\section{BIBLIOGRAFÍA}

1. Yang J, Foster CS. Squamous cell carcinoma of the conjunctiva. Int Ophthalmol Clin 1997; 37 :73-85. 
2. Mahmood MA, Al-Rajhi A, Riley F, Karcioglu ZA. Sclerokeratitis: an unusual presentation of squamous cell carcinoma of the conjunctiva. Ophthalmology 2001; 108: 553 558.

3. Newton R, Ferlay J, Reeves G, Beral V, Parkin DM. Effect of ambient solar ultraviolet radiation on incidence of squamous cell carcinoma of the eye. Lancet 1966; 347: 1450-1451.
4. Newton $R$. A review of the aetiology of squamous cell carcinoma of the conjunctiva. Br J Cancer 1996; 74: 15111513.

5. Lindenmuth KA, Sugar A, Kincaid MC, Nelson CC, Cornstock CP. Invasive squamous cell carcinoma of the conjunctiva presenting as necrotizing scleritis with scleral perforation and uveal prolapse. Surv Ophthalmol 1988; 33: $50-54$. 